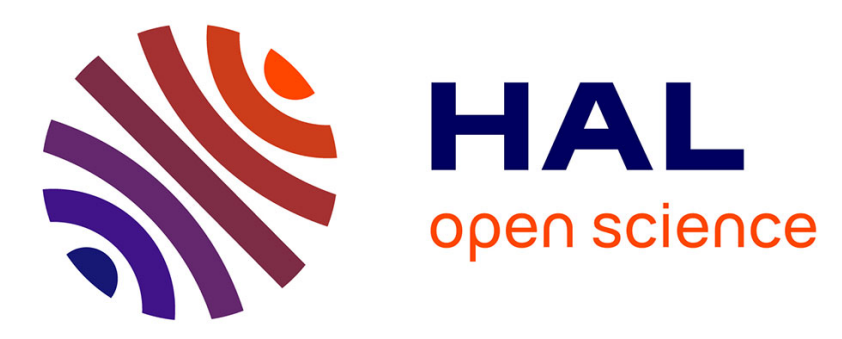

\title{
An analytical model of evaporation efficiency for unsaturated soil surfaces with an arbitrary thickness
}

Olivier Merlin, Al Bitar Ahmad, Vincent Rivalland, Pierre Béziat, Eric Ceschia, Gérard Dedieu

\section{- To cite this version:}

Olivier Merlin, Al Bitar Ahmad, Vincent Rivalland, Pierre Béziat, Eric Ceschia, et al.. An analytical model of evaporation efficiency for unsaturated soil surfaces with an arbitrary thickness. 2010. hal00525063

\section{HAL Id: hal-00525063 \\ https://hal.science/hal-00525063}

Preprint submitted on 11 Oct 2010

HAL is a multi-disciplinary open access archive for the deposit and dissemination of scientific research documents, whether they are published or not. The documents may come from teaching and research institutions in France or abroad, or from public or private research centers.
L'archive ouverte pluridisciplinaire HAL, est destinée au dépôt et à la diffusion de documents scientifiques de niveau recherche, publiés ou non, émanant des établissements d'enseignement et de recherche français ou étrangers, des laboratoires publics ou privés. 


\title{
An analytical model of evaporation efficiency for unsaturated soil
}

\author{
surfaces with an arbitrary thickness
}

\author{
Olivier MerLin * \\ Ahmad Al Bitar \\ VinCENT RivalLAND \\ PierRe BÉziat \\ ERIC CESCHIA \\ GÉrard Dedieu
}

Centre d'Etudes Spatiales de la Biosphère, Toulouse, France

\footnotetext{
${ }^{*}$ Corresponding author address: Olivier Merlin, Centre d'Etudes Spatiales de la Biosphère, 31401, Toulouse Cedex 9, France.

E-mail: olivier.merlin@cesbio.cnes.fr
} 


\begin{abstract}
Analytical expressions of evaporative efficiency over bare soil (defined as the ratio of actual to potential soil evaporation) have been limited to soil layers with a fixed depth and/or to specific atmospheric conditions. To fill the gap, a new analytical model is developed for arbitrary soil thicknesses and varying boundary layer conditions. The soil evaporative efficiency is written $\left[0.5-0.5 \cos \left(\pi \theta_{L} / \theta_{\max }\right)\right]^{P}$ with $\theta_{L}$ being the water content in the soil layer of thickness $L, \theta_{\max }$ the soil moisture at saturation and $P$ a function of $L$ and potential soil evaporation. This formulation predicts soil evaporative efficiency in both energy-driven and moisture-driven conditions, which correspond to $P<0.5$ and $P>0.5$ respectively. For $P=0.5$, an equilibrium state is identified when retention forces in the soil compensate the evaporative demand above the soil surface. The approach is applied to in situ measurements of actual evaporation, potential evaporation and soil moisture at five different depths $(5,10$, 30 and 60/100 cm) collected in summer at two sites in southwestern France. It is found that (i) soil evaporative efficiency cannot be considered as a function of soil moisture only, since it also depends on potential evaporation, (ii) retention forces in the soil increase in reaction to an increase of potential evaporation and (iii) the model is able to accurately predict soil evaporation process for soil layers with an arbitrary thickness up to $100 \mathrm{~cm}$. This new model representation is expected to facilitate the coupling of land surface models with multi-sensor (multi-sensing-depth) remote sensing data.
\end{abstract}




\section{Introduction}

Evaporation over bare and partially vegetated soil surfaces is one of the main components of the exchange at the land surface-atmosphere interface (e.g. Lawrence et al. 2007). To predict soil evaporation, two distinct approaches can be used, namely the mechanistic or physical and the simplified or phenomenological approach (Mahfouf and Noilhan 1991). Both are strongly complementary. On one hand, the mechanistic approach (e.g. Chanzy and Bruckler 1993; Yamanaka et al. 1998) describes the soil at the near-surface as a multi-layer system, and physically represents the mass and heat exchange between soil layers and the atmosphere. On the other hand, the simplified approach (e.g. Noilhan and Planton 1989; Mihailović et al. 1993) describes the soil as a single layer system and empirically represents actual evaporation using a resistance (or factor) that accounts for evaporative losses in relation to the evaporative demand also called potential evaporation. Mechanistic models are very useful to understand and describe at local scale the physical processes involved in evaporation including gravitary drainage, capillary rise and vapor diffusion. However, their complexity makes them impractical for spatial applications (Mahfouf and Noilhan 1991). Chanzy et al. (2008) have implemented such a mechanistic model in a spatial context with reasonable accuracy. Nevertheless, their approach essentially relies on pedotransfer functions, which are fraught to uncertainties as they depend on the soil texture, soil structure (poresize distribution and connectivity) and soil aggregates at various depths and the presence of biomass. In fact, the ground evaporation modeled by the land surface schemes of current general circulation models is exclusively based on simplified formulations (Pitman 2003). Phenomenological expressions are more convenient for large scale applications because they 
have a minimum of input parameters. Nevertheless, the physical interpretation of their parameters may be difficult due to the more or less empirical nature of simplified approaches (Shuttleworth and Wallace 1985).

A type of simplified approach is based on the resistance $r_{s s}$ to the diffusion of vapor in large soil pores (e.g. Monteith 1981; Camillo and Gurney 1986; Passerat de Silans 1986; Kondo et al. 1990; Sellers et al. 1992; Daamen and Simmonds 1996). During the past forty years, many different expressions of $r_{s s}$ have been developed, and most studies have documented difficulties with the uniqueness of the resistance formulation. Broadly, two main inconsistancies with the resistance representation have been stated. For practical reasons, $r_{s s}$ is generally defined using the soil surface temperature instead of the soil temperature at the depth where vaporization occurs (van de Griend and Owe 1994). This causes systematic underestimation of soil evaporation in dry conditions (Yamanaka et al. 1997). Moreover, the resistance-based approach is only valid when water flow is limited by vapor transport diffusion. In particular, it does not apply to the conditions when water flow is mainly driven by gravity (Salvucci 1997) or capillarity (Saravanapavan and Salvucci 2000) forces. Both inconsistancies weaken the resistance representation, and make its implementation into land surface models problematic.

Another simplified approach is based on a factor that directly expresses the ratio of actual to potential evaporation as a function of surface soil moisture. This ratio is commonly called soil evaporative efficiency and noted $\beta$. Although early formulations of $\beta$ have been based on surface soil moisture only (Deardorff 1978; Noilhan and Planton 1989; Lee and Pielke 1992; Chanzy and Bruckler 1993; Komatsu 2003), more recent formulations use additional variables like wind speed and/or potential evaporation to account for the variabilities in $\beta$ 
that are not described by soil moisture alone (Chanzy and Bruckler 1993; Komatsu 2003). In particular, soil evaporative efficiency was found to decrease with wind speed in Perrier (1975); Kondo et al. (1990); Chanzy and Bruckler (1993); Yamanaka et al. (1997); Komatsu (2003). The decrease of $\beta$ with potential evaporation was observed in Chanzy and Bruckler (1993); Daamen and Simmonds (1996). Although all authors agree about the dependance of soil evaporative efficiency to atmospheric conditions, there is no clear consensus about how best to analytically express $\beta$. In fact, identifying the variables that impact on $\beta$ is complicated by two factors (i) each $\beta$ formulation has a specific sensitivity to soil and atmospheric conditions, and (ii) evaporation is a complex phenomenon whose processes (e.g. vapor diffusion in the surface soil pore and vapor transport in air) are essentially coupled (Philip 1957).

Concurrently with the development of simplified approaches, some authors have demonstrated the usefulness of remote sensing data to monitor bare soil evaporation, and conversely, to calibrate evaporation models. Soil evaporation can be estimated from remotely-sensed surface skin temperature (e.g. Nishida et al. 2003) or using the near-surface soil moisture retrieved from microwave data (e.g. Kustas et al. 1993). However, the use of remote sensing data requires a soil evaporation model whose representation matches the sensing depth (Chanzy and Bruckler 1993; Yamanaka et al. 1997; Komatsu 2003). This is complicated by the fact that sensing depth varies with the spectral band of observation. In particular, the sensing depth is approximately $1 \mathrm{~mm}$ in the thermal band, $1 \mathrm{~cm}$ at $\mathrm{C}$-band and $5 \mathrm{~cm}$ at L-band.

The coupling of land surface schemes with remote sensing data is expected to be facilitated by the development of a robust parameterization of evaporation for an arbitrary soil 
thickness (Komatsu 2003). However, a major limitation of existing simplified models is their sensitivity to soil thickness (Fuchs and Tanner 1967; Lee and Pielke 1992; Wallace 1995; Daamen and Simmonds 1996; Yamanaka et al. 1997, 1998; Komatsu 2003). All expressions of $r_{s s}$ and $\beta$ have been developed and calibrated using a given thickness of soil. For instance, Sellers et al. (1992) uses a 5 cm soil layer, van de Griend and Owe (1994) a $1 \mathrm{~cm}$ soil layer and Komatsu (2003) a thin layer of 1-3 mm. Consequently, a given expression of soil evaporation corresponds to a specific soil thickness or, at the very least, a new parameter set is required when applying the model to a different soil layer.

In this context, the paper seeks to derive a simple analytical expression of evaporative efficiency $\beta$ for soil surfaces with an arbitrary thickness. The study is based on data collected at two sites in southwestern France during a bare soil period. Two existing models of soil evaporative efficiency are first described. One was developed for a soil layer of 0-5 cm (Sellers

et al. 1992), and the other for a thin layer of several millimeters (Komatsu 2003). A new $\beta$ formulation is then derived by comparing the shape of those analytical expressions. Finally, the sensitivity of model parameters to varying soil and atmospheric conditions is assessed at the two sites.

\section{Data Collection and Pre-Processing}

Data collected at two sites near Auradé $\left(43.549^{\circ} \mathrm{N} ; 1.108^{\circ} \mathrm{E}\right)$ and Lamasquère $\left(43.493^{\circ} \mathrm{N}\right.$; $\left.1.237^{\circ} \mathrm{E}\right)$ in southwestern France are described below. Both sites are at an altitude of about $200 \mathrm{~m}$ and are separated by $12 \mathrm{~km}$. The mean annual temperature and precipitation calculated over 30 years (1961-1990) are $12.9^{\circ} \mathrm{C}$ and $656 \mathrm{~mm}$, respectively. Soil texture can be 
classified as clay for Lamasquère with sand and clay fractions of $12 \%$ and $54 \%$ respectively, and as clay loam (or silty clay loam) for Auradé with sand and clay fractions of $21 \%$ and $31 \%$, respectively.

Auradé and Lamasquère are currently equiped with meteorological and Eddy Correlation flux stations, providing continuous data with a 30-minute time step since mid 2004. Soil moisture $\theta$ is measured at three depths in the near-surface: $5 \mathrm{~cm}, 10 \mathrm{~cm}$ and $30 \mathrm{~cm}$. Additional measurements are made at $60 \mathrm{~cm}$ and $100 \mathrm{~cm}$ depth at Auradé and Lamasquère, respectively. A soil moisture value corresponds to the average of the measurements made by three sensors (CS615 or CS616, Campbell Scientific, Logan Utah, USA) buried at the same depth and separated by about $1 \mathrm{~m}$. Each sensor is calibrated using gravimetric measurements. During the 2005-2007 period, the mean and maximum standard deviation of the measurements made by three replicates is 0.014 and 0.044 vol./vol. at Auradé and 0.019 and 0.068 vol./vol. at Lamasquère, respectively. Any work (tillage, planting and harvesting) performed in the field is manually reproduced at the station site. Ploughing is reproduced in the superficial $(0-5 \mathrm{~cm})$ soil layer only to minimize disturbances on permanently buried sensors. The leaf area index, plant area index, biomass and plant height are regularly measured throughout the growing period. Further details on instrumentation and site characterization can be found in Béziat et al. (2009).

A bare soil period is selected in 2005-2007, which is representative of the climatic normals calculated over 30 years (Béziat et al. 2009). As potential evaporation is expected to be higher in summer than in winter, the summer months that followed harvest are chosen. In practice, the study period goes from 30 June (harvest on 29 June 2006) to 28 September 2006 at Auradé and from 12 July (harvest on 11 July 2005) to 14 September 2005 at Lamasquère. 
Selected bare soil periods are in fields of wheat followed by sunflower and triticale followed by corn at Auradé and Lamasquère, respectively. No ploughing is undertaken during those periods. At Lamasquère, the study period is restricted to two months due to a significant plant re-growth observed in late summer 2005. The time series of soil moisture measurements for the selected bare soil periods are plotted in Figure 1.

Four soil layers $L 1, L 2, L 3$ and $L 4$ are defined as 0-5, 0-10, 0-30, and 0-60 (or 0-100) $\mathrm{cm}$, respectively. To estimate the integrated value of moisture over $L 1, L 2, L 3$ and $L 4$, the point measurements made at 5, 10, 30 and 60 (or 100) cm are linearly interpolated. Since no measurement is available at the soil surface, soil moisture is assumed to be uniformly distributed in the first $0-5 \mathrm{~cm}$ layer. Hence, integrated soil moisture is estimated as $\theta_{L 1}=$ $\left.\theta_{5 \mathrm{~cm}} ; \theta_{L 2}=\left[\theta_{L 1}+\left(\theta_{5 \mathrm{~cm}}+\theta_{10 \mathrm{~cm}}\right) / 2\right] / 2, \theta_{L 3}=\left[\theta_{L 2}+2 \times\left(\theta_{10 \mathrm{~cm}}+\theta_{30 \mathrm{~cm}}\right) / 2\right)\right] / 3$, and $\theta_{L 4}=$ $\left[\theta_{L 3}+\left(\theta_{30 \mathrm{~cm}}+\theta_{60 \mathrm{~cm}}\right) / 2\right] / 2$. Note that $\theta_{60 \mathrm{~cm}}$ is defined solely for Auradé and $\theta_{100 \mathrm{~cm}}$ is defined solely for Lamasquère. An example of soil moisture profile at the experimental sites is presented in the schematic diagram of Figure 2. The mean soil moisture for each layer is estimated as the area defined by the graph divided by the thickness $L$.

The observed soil evaporative efficiency $\beta_{o b s}$ is computed as:

$$
\beta_{o b s}=\frac{L E_{o b s}}{L E p}
$$

with $L E_{o b s}$ being the soil evaporation measured by the Eddy Correlation system and $L E p$ the potential evaporation. Different methods can be used to estimate potential evaporation. In this study, potential evaporation is estimated using the Penman equation:

$$
L E p=\frac{\Delta(R n-G)+\rho C_{P}\left(e_{s a t}\left(T_{a}\right)-e_{a}\right) / r_{a h}}{\Delta+\gamma}
$$

with $\Delta$ being the slope of the saturation vapor curve $\left(\mathrm{Pa} \mathrm{K} \mathrm{K}^{-1}\right), R n$ the soil net radiation 
$\left(\mathrm{W} \mathrm{m} \mathrm{m}^{-2}\right), G$ the ground heat flux measured at $5 \mathrm{~cm}$ depth $\left(\mathrm{W} \mathrm{m}^{-2}\right), \rho$ the density of air $\left(\mathrm{kg} \mathrm{m}^{-3}\right), C_{P}$ the specific heat capacity of air $\left(\mathrm{J} \mathrm{kg}^{-1} \mathrm{~K}^{-1}\right), \gamma$ the psychrometric constant $\left(\mathrm{Pa} \mathrm{K} \mathrm{K}^{-1}\right), e_{\text {sat }}\left(T_{a}\right)$ the saturated vapor pressure $(\mathrm{Pa})$ at air temperature, $e_{a}$ the measured air vapor pressure $(\mathrm{Pa})$ and $r_{a h}$ the aerodynamic resistance to heat transfer $\left(\mathrm{s} \mathrm{m}^{-1}\right)$. The saturated vapor pressure in Equation (2) is generally computed as:

$$
e_{\text {sat }}\left(T_{a}\right)=611 \exp \left[17.27 T_{a} /\left(T_{a}+237.3\right)\right]
$$

with $T_{a}$ in ${ }^{\circ} \mathrm{C}$. The aerodynamic resistance $r_{a h}$ is estimated as in Choudhury et al. (1986):

$$
r_{a h}=\frac{r_{a h 0}}{(1+R i)^{\eta}}
$$

with $r_{a h 0}$ being the aerodynamic resistance which neglects natural convection and $R i$ the Richardson number (unitless) which represents the importance of natural relative to the forced convection. The $r_{a h 0}$ term is computed as:

$$
r_{a h 0}=\frac{1}{k^{2} u}\left[\ln \left(\frac{Z}{z_{0 m}}\right)\right]^{2}
$$

with $k$ being the von Karman constant, $u$ the wind speed measured at the reference height $Z$ and $z_{0 m}$ the soil roughness. At both sites, soil roughness is set to $0.005 \mathrm{~m}$ as in Liu et al. (2007). The Richardson number is computed as:

$$
R i=\frac{5 g Z\left(T-T_{a}\right)}{T_{a} u^{2}}
$$

with $g$ being the gravitational constant $\left(\mathrm{m} \mathrm{s}^{-2}\right), T$ the surface soil temperature measured at $1 \mathrm{~cm}$ depth $(\mathrm{K})$ and $T_{a}$ the air temperature in K. In Equation (4), the coefficient $\eta$ is set to 0.75 in unstable conditions $\left(T>T_{a}\right)$ and to 2 in stable conditions $\left(T<T_{a}\right)$.

Data are averaged between 10 am and $4 \mathrm{pm}$ and only the days with more than three acquisition times (including the measurement of all the required input variables) are kept. 
During the bare soil periods selected at Auradé and Lamasquère, the data set is composed of 60 and 61 days, respectively. As an assessment of the uncertainty in daily soil evaporative efficiency, the daily variability of observed $\beta$ is computed as the standard deviation of the 30min measurements made between 10 am and 4 pm. At both sites, the mean daily variability is 0.06-0.09 during the three summer months (summer 2006 at Auradé and summer 2005 at Lamasquère) and is 0.12 during the autumn and winter months that followed the study period. The higher daily variability in observed $\beta$ is due to lower values of $L E$ and $L E p$ in autumn-winter, while random uncertainties in $L E$ and $L E p$ can be assumed to be relatively constant. In particular, the mean potential evaporation is about $300 \mathrm{~W} \mathrm{~m}^{-2}$ in summer and $200 \mathrm{~W} \mathrm{~m}^{-2}$ in autumn-winter. Note that the variability of $\beta$ between 10 am and $4 \mathrm{pm}$ may also be partly due to the daily cycle of soil moisture profile near the surface induced by capillary rises during the night and evaporation during the day (Chanzy 1991).

Figure 3 plots daily soil evaporative efficiency against $0-5 \mathrm{~cm}$ soil moisture for each site separately. One observes that $\beta$ generally increases with near-surface soil moisture. However, the scatter in observed $\beta$ increases with $\beta$. This is the rationale for including some atmospheric variables in the analytical formulations $\beta(\theta)$.

\section{Two Complementary Analytical Models}

Two analytical models of soil evaporative efficiency are presented below. One was originally developed for a 0-5 cm soil layer (Sellers et al. 1992) and the other for a thin layer of several millimeters (Komatsu 2003). Both models are chosen to illustrate (i) the resistanceand factor-based approaches and (ii) the change in the shape of $\beta(\theta)$ when increasing or 
decreasing soil thickness.

a. Resistance approach for the 0-5 cm layer (Model 1)

Soil evaporation efficiency can be expressed using a resistance term that reduces evaporation below the potential rate (Monteith 1981):

$$
\beta_{1}=\frac{r_{a h}}{r_{a h}+r_{s s}}
$$

with $r_{s s}$ being the soil evaporation resistance $\left(\mathrm{s} \mathrm{m}^{-1}\right)$. Following the formulation of Sellers et al. (1992), soil resistance can be written as:

$$
r_{s s}=\exp \left(A_{1}-B_{1} \theta_{5 c m} / \theta_{\max }\right)
$$

with $\theta_{5 \mathrm{~cm}}$ being the $0-5 \mathrm{~cm}$ soil moisture, $\theta_{\max }$ the maximum soil moisture and $A_{1}$ and $B_{1}$ two best-fit parameters. By setting the maximum soil moisture to the soil moisture at saturation, $A_{1}$ and $B_{1}$ are generally close to 8 and 5 , respectively (Sellers et al. 1992; Kustas et al. 1998; Crow et al. 2008). In this study, the soil moisture at saturation is estimated using the formula of Cosby et al. (1984):

$$
\theta_{\max }=0.489-0.126 f_{\text {sand }}
$$

with $f_{\text {sand }}$ being the sand fraction. Maximum soil moisture is estimated as 0.47 and 0.46 vol./vol. for Auradé and Lamasquère, respectively.

As a first assessment of the resistance-based model of Equation (8), Figure 4 plots the soil evaporative efficiency simulated by Model 1 as a function of soil moisture, for a soil with a high clay content and a wind speed of $2 \mathrm{~m} \mathrm{~s}^{-1}$. The maximum soil moisture $\theta_{\max }$ is computed 
using Equation (9) with a sand fraction of $0.20\left(\theta_{\max }=0.46\right.$ vol./vol.). Parameters $A_{1}$ and $B_{1}$ are set to 8 and 7 . It is apparent that the curve is non-linear and has an inflexion point at half of the maximum soil moisture.

b. A phenomenological expression for a thin layer (Model 2)

Alternatively to the resistance approach, soil evaporation efficiency can be directly expressed as a function of surface soil moisture (Deardorff 1978). For instance, a simple expression of soil evaporative efficiency was developed by Komatsu (2003) using a laboratory experimental data set:

$$
\beta_{2}=1-\exp \left(-\theta_{m m} / \theta_{c}\right)
$$

with $\theta_{m m}$ being the soil moisture in the first $1-3 \mathrm{~mm}$ of the surface and $\theta_{c}$ a semi-empirical parameter that depends on soil type and wind speed:

$$
\theta_{c}=\theta_{c 0}\left(1+r_{a h}^{r e f} / r_{a h}\right)
$$

with $\theta_{c 0}$ being a soil-dependent parameter ranging from $\sim 0.01 \mathrm{vol} . / \mathrm{vol}$. to $0.04 \mathrm{vol} / \mathrm{vol}$. for sand and clay respectively, and $r_{a h}^{r e f}$ a reference aerodynamic resistance estimated to $\sim 100 \mathrm{~s}$ $\mathrm{m}^{-1}$ in Komatsu (2003).

Figure 4 plots the soil evaporative efficiency simulated by Model 2 as a function of soil moisture, for typical clay and a wind speed of $2 \mathrm{~m} \mathrm{~s}^{-1}$. When comparing Model 1 and 2, one observes that the inflexion point of Model 1 is no more apparent with Model 2. In particular, the curve switches from a $S$ - to $\Gamma$-shaped form when decreasing the thickness of the soil layer engaged in the evaporation process. This switch was already observed using both data collected in laboratory (Komatsu 2003) and data generated by a mechanistic 
model (Chanzy and Bruckler 1993). In those studies, the $S$-shaped form of soil evaporative efficiency was attributed to the non uniformity in the vertical distribution of water in thick soil layers. In particular, the reduction of evaporation in a drying soil is generally related to the formation of a dry surface layer above the evaporative front (Fritton et al. 1967; Yamanaka et al. 1998).

\section{A General Formulation}

In the previous section, the difference in the shape of $\beta(\theta)$ was attributed to the thickness of the soil layer engaged in the evaporation process. However, no formulation of $\beta(\theta)$ for various soil thicknesses currently exists. To fill the gap, a general expression of soil evaporative efficiency is proposed:

$$
\begin{aligned}
\beta_{3}=\left[\frac{1}{2}-\frac{1}{2} \cos \left(\pi \theta_{L} / \theta_{\max }\right)\right]^{P} & \text { for } \theta_{L} \leq \theta_{\max } \\
\beta_{3}=1 & \text { for } \theta_{L}>\theta_{\max }
\end{aligned}
$$

with $\theta_{L}$ being the water content in the soil layer of thickness $L$ and $P$ a parameter. This expression noted Model 3 was already used by Noilhan and Planton (1989); Jacquemin and Noilhan (1990); Lee and Pielke (1992) with $\theta_{\max }$ equal to the soil moisture at field capacity and with $P=1$ or $P=2$. However, the link between $P$ and soil thickness had not been established. In this study, parameter $P$ in Equation (12) is expressed as:

$$
P=\left(\frac{1}{2}+A_{3} \frac{L-L 1}{L 1}\right) \frac{L E p}{B_{3}}
$$

with $L 1$ being the thinnest represented soil layer (here $0-5 \mathrm{~cm}$ ), and $A_{3}$ (unitless) and $B_{3}$ $\left(\mathrm{W} \mathrm{m}^{-2}\right)$ two best-fit parameters that a priori depend on soil texture and structure. 
In Noilhan and Planton (1989) and Lee and Pielke (1992), the maximum soil moisture $\theta_{\max }$ was set to the soil moisture at field capacity. In this study, the maximum soil moisture in Model 1 and 3 is set to the soil moisture at saturation. The rationale is that potential evaporation, which is a quasi instantaneous process and a threshold value, is physically reached at soil saturation and not at field capacity. Note that the shape offered by Equation (12) leads to an asymptotic behavior at $\beta=1$. Consequently, the soil evaporative efficiency modeled at field capacity is very close to 1 . This is consistent with the representation of the models in Noilhan and Planton (1989) and Lee and Pielke (1992).

The parameter $P$ in Equation (13) represents an equilibrium state controlled by (i) retention forces in the soil, which increase with soil thickness $L$ and (ii) evaporative demands at the soil surface $L E p$, which notably depend on solar radiation and wind speed. Inspection of Equation (13) indicates that both retention force and evaporative demand make parameter $P$ increase, as if an increase of $L E p$ at the soil surface would make the retention force in the soil greater. Moreover, Equation (12) predicts a decrease in soil evaporative efficiency when exponent $P$ increases. Consequently, the soil evaporative efficiency predicted by Model 3 decreases when $L E p$ increases. This is consistent with the results obtained with the numerical experiment of Chanzy and Bruckler (1993). As potential evaporation is an increasing function of wind speed (see Equations (2), (4) and (5)), this is also consistent with the experimental observation of Komatsu (2003) that $\beta$ decreases with wind speed (or more specifically increases with the aerodynamic resistance $r_{a h}$ ). The decrease of $\beta$ with $L E p$ can be interpreted as an increase of retention forces in the soil, in reaction to an increase of evaporative demands at the soil surface. Chanzy and Bruckler (1993) demonstrated that $\beta$ dependency to $L E p$ is the consequence of the shape of the soil moisture profile within the 
soil moisture thickness $(0-5 \mathrm{~cm})$. For a given soil moisture average, soil is dryer at the soil surface when the evaporative demand is strong.

Figure 4 plots the evaporative efficiency simulated by Model 3 as a function of soil moisture for two different values of $P$. As for Model 1 , the maximum soil moisture $\theta_{\max }$ is set to 0.46 vol./vol.. One observes that the $S$-shaped curve of $\beta_{3}$ is quasi-similar to that of $\beta_{1}$ by setting $P=1$, and the $\Gamma$-shaped curve of $\beta_{3}$ is quasi-similar to that of $\beta_{2}$ by setting $P=0.2$.

Figure 5 plots the soil evaporative efficiency simulated by Model 3 as a function of soil moisture for different values of $P$ ranging from 0.1 to 4 . The shape of modeled $\beta(\theta)$ becomes very assymetrical for $P$ values higher than 1, with an inflexion point that slides towards the value of maximum soil moisture. The assymetrical behavior of soil evaporative efficiency was already observed in Chanzy and Bruckler (1993) using data generated by a mechanistic model. For $P>0.5$, the slope $d \beta / d \theta$ at $\theta=0$ is zero, meaning that $\beta$ increases rapidly as a function of soil moisture so as to reach the value 1 at $\theta=\theta_{\max }$. Consequently, $P>0.5$ corresponds to moisture-driven conditions. For $P<0.5$, the slope $d \beta / d \theta$ at $\theta=0$ is infinite, meaning that $\beta$ is close to 1 regardless of soil moisture conditions. Consequently, $P<0.5$ corresponds to energy-driven conditions. An equilibrium state is visible at $P=0.5$ where soil retention forces balance atmospheric evaporative demands. This equilibrium point is identified in Figure 5 by a non zero slope at zero soil moisture. Note that the terms "energydriven" and "moisture-driven" are not related to the different phases of evaporation (phase I: wet soil; phase II: drying soil; phase III: very dry soil). In this study, they are used to distinguish two different behaviors of soil evaporative efficiency with respect to the soil moisture observed in a given soil layer. 


\section{Application}

Models 1, 2 and 3 are applied to Auradé and Lamasquère data sets. The three models are intercompared using default and site-specific parameters.

\section{a. Default parameters}

Models 1, 2 and 3 are first applied using default parameters. For Model 1, best-fit parameters $A_{1}$ and $B_{1}$ are set to 8.2 and 4.3 as in Sellers et al. (1992); Crow et al. (2008). Figure 6 plots modeled versus observed evaporative efficiency at each site. It is apparent that uncalibrated Model 1 underestimates evaporative efficiency at both sites. Table 1 lists the root mean square difference, correlation coefficient, slope and mean difference between simulated and observed data. The poor performance of uncalibrated Model 1 is notably due to a slope much lower than 1 , about 0.13 and 0.30 for Auradé and Lamasquère respectively.

For Model 2, $\theta_{c 0}$ is set to $0.04 \mathrm{vol}$./vol., which is the typical value for clay (Komatsu 2003). Figure 6 plots modeled versus observed evaporative efficiency at each site. Model 2 severely overestimates observations at both sites and is poorly sensitive to soil moisture.

For Model 3, the exponent $P$ is set to 2 as in Lee and Pielke (1992). Figure 6 plots the evaporative efficiency simulated by uncalibrated Model 3 as a function of observed evaporative efficiency for each site. Statistical results in Table 1 indicate a slight improvement compared to Model 1 predictions. However, the error in simulated soil evaporative efficiency (0.14 and 0.18 for Auradé and Lamasquère respectively), is still much higher than the standard deviation $(<0.1)$ of $30-$ min $\beta$ observations between 10 am and $4 \mathrm{pm}$.

Note that the poor results obtained with default parameters is not particular to our case 
study. All studies dealing with simplified models of soil evaporation have documented the need for a site-specific calibration.

\section{b. Site-specific parameters}

To assess the performance of Model 1, 2 and 3, simulations are re-done using site-specific parameters. Simultaneous measurements of evaporation, wind speed, relative humidity and soil moisture are used to adjust $\left(A_{1}, B_{1}\right), \theta_{c 0}$ and $\left(A_{3}, B_{3}\right)$ at Auradé and Lamasquère. The calibration approach is detailed below for each model separately.

\section{1) MODEL 1}

By inverting Equation (7), soil resistance is expressed as:

$$
r_{s s}=\frac{1-\beta_{o b s}}{\beta_{o b s}} r_{a h}
$$

Equation (8) is then re-written as:

$$
\ln \left(\frac{1-\beta_{o b s}}{\beta_{o b s}} r_{a h}\right)=A_{1}+B_{1} \theta_{5 c m} / \theta_{\max }
$$

Figure 7 plots $\ln \left(r_{s s}\right)$ as a function of $\theta_{5 \mathrm{~cm}}$. One observes that $\ln \left(r_{s s}\right)$ generally decreases with soil moisture. However, the deviation around the linear fit is relatively large for both sites. Therefore, near-surface soil moisture does not explain all variations in soil resistance. Site-specific $A_{1}$ and $B_{1}$ are obtained as the ordinate at $\theta_{5 \mathrm{~cm}}=0$ and the slope of the linear regression between $\ln \left(r_{s s}\right)$ and $\theta_{5 c m} / \theta_{\max }$, respectively. Values for Auradé and Lamasquère are reported in Table 2. Calibrated values are significantly higher than those $\left(A_{1}=8.2\right.$, $\left.B_{1}=4.3\right)$ in Sellers et al. (1992). This difference is probably explained by the depth of soil 
moisture measurements. In Sellers et al. (1992), the near-surface soil moisture was defined in the $0-5 \mathrm{~cm}$ soil layer, whereas in our case study, soil moisture measurements are made at $5 \mathrm{~cm}$ depth.

Figure 8 plots the soil evaporative efficiency simulated by calibrated Model 1 as a function of observed soil evaporative efficiency. The correlation and slope appear to be significantly better than those with uncalibrated parameters (see Figure 6). Table 3 lists the root mean square difference, correlation coefficient, slope and mean difference between simulated and observed $\beta$. By calibrating $A_{1}$ and $B_{1}$, the error is decreased from 0.21 to 0.13 and from 0.17 to 0.16 for Auradé and Lamasquère respectively. The correlation coefficient and slope between simulated and observed $\beta$ are much improved. Those results emphasize the need for calibrating the soil parameters involved in evaporation process.

\section{2) MODEL 2}

By inverting Equation (10), parameter $\theta_{c}$ is expressed as:

$$
\theta_{c}=-\frac{\theta_{5 c m}}{\ln \left(1-\beta_{o b s}\right)}
$$

and parameter $\theta_{c 0}$ is expressed as:

$$
\theta_{c 0}=-\frac{\theta_{5 c m}}{\left(1+r_{a h}^{r e f} / r_{a h}\right) \ln \left(1-\beta_{o b s}\right)}
$$

A value of $\theta_{c 0}$ is obtained on each observation day. For each site, the calibrated $\theta_{c 0}$ is set to the average of the values retrieved on all dates. Calibration results are reported in Table 2. The standard deviation of daily $\theta_{c 0}$ is estimated as 0.14 (41\% of the mean) and 0.13 (36\% of the mean) for Auradé and Lamasquè, respectively. The high variability in $\theta_{c 0}$ is probably due 
to the inadequacy between the representation of Model 2 and the depth $(5 \mathrm{~cm})$ at which soil moisture measurements are made. Figure 8 plots the soil evaporative efficiency simulated by Model 2 as a function of observed soil evaporative efficiency. Calibrating $\theta_{c 0}$ significantly reduces the large positive bias on $\beta_{2}$. However, the slope between modeled and observed soil evaporative efficiency is still very low (see Table 3). These results indicate that Model 2 is not adapted for predicting evaporative efficiency using soil moisture measurements at $5 \mathrm{~cm}$ depth.

\section{3) Model 3}

By inverting Equation (12), exponent $P$ is expressed as:

$$
P=\frac{\ln \beta_{o b s}}{\ln \left[0.5-0.5 \cos \left(\pi \theta_{L} / \theta_{\max }\right)\right]}
$$

Following Equation (13), parameters $A_{3}$ and $B_{3}$ can be estimated from the coefficients of a linear regression between the parameter $P$ retrieved from Equation (18) and observed $L E p$. Figure 9 plots retrieved $P$ as a function of potential evaporation for each site and for each soil layer. Scatterplots indicate that retrieved $P$ generally increases with $L E p$. $P$ is parameterized for each layer by fitting the data with a straight line. Since $P$ should be zero at $L E p=0$, the straight line is defined by two points: the origin point, and a point located the furthest from the origin. In practice, the second point is chosen as the barycentre of all the points with $L E p>300 \mathrm{~W} \mathrm{~m}^{-2}$. An interesting feature is that the slope of the straight line $P / L E p$ is well correlated with soil thickness. Figure 10 plots the slope as a function of normalized thickness $(L-L 1) / L 1$. The correlation coefficient between slope and $L$ is 0.94 and 0.99 for Auradé and Lamasquère, respectively. Parameters $A_{3}$ and $B_{3}$ are finally 
calibrated from the linear regression presented in Figure 10 and values are reported in Table 2 .

Figure 8 plots the soil evaporative efficiency simulated by calibrated Model 3 as a function of observed soil evaporative efficiency. Model 3 appears to perform better than Model 1. Moreover, Model 3 seems to be quite stable for all layers including the layer of $100 \mathrm{~cm}$ thick. Table 3 lists the root mean square difference, correlation coefficient, slope and mean difference between simulated and observed $\beta$. The error on simulated soil evaporative efficiency ranges from 0.07 to 0.10 , which is similar to the daily variability $(0.06-0.09)$ of observations between $10 \mathrm{am}$ and $4 \mathrm{pm}$. Statistical results indicate that the new formulation is more accurate than the resistance-based approach, and is more robust since it applies to different soil thicknesses with a similar accuracy.

\section{Stability of Parameter $P$}

The new formulation of soil evaporative efficiency in Equation (12) was successfully tested with data collected at two sites. However, no proof is given that physical processes are realistically represented since the model is still empirically based. This section aims to interpret the variabilities of parameter $P$ in terms of soil and atmospheric conditions. In particular, the stability of $P$ is analyzed with respect to (i) wind speed, (ii) soil moisture profile and (iii) soil type. 
a. Wind speed

Equation (13) parameterizes $P$ as a function of potential evaporation. To assess the relevance of this parameterization, the correlation between $P$, potential evaporation $L E p$ and wind speed $u$ is quantified and interpreted using Principal Component (PC) analysis. PC analysis is a usefull tool to describe complex data sets (e.g. Jolliffe 2002). It expresses the variables of a data set as a linear function of a smaller set of new variables called PCs. This simplification allows to graphically represent and summarize the key features of the data set, revealing the underlying structure of the data. Herein, one objective of the analysis in PCs is to better quantify and understand the potential impact of wind speed on parameter $P$.

Figure 11 is known as the correlation circle. It shows a projection in the two first PCs space of the initial variables including retrieved $P$ parameter, potential evaporation $L E p$ and wind speed $u$. Interpretation of the correlation circle is based on the relative position of arrows. Two variables are positively correlated when arrows are close together; two variables are negatively correlated when arrows point in the opposite direction; and two variables are not linearly correlated when arrows are orthogonal. Figure 11 indicates that the arrows for $P$ and $L E p$ are close for both Auradé and Lamasquère sites, which justifies the linear relationship between $P$ and $L E p$ in Equation (13).

Figure 11 also indicates that the arrow for $u$ is quasi orthogonal to that for $P$, meaning that $P$ is practically not correlated with $u$. Consequently, wind speed does not appear to be a significant factor in the parameterization of soil evaporative efficiency. Chanzy and Bruckler (1993) have shown (theoretically and experimentally) that soil evaporative efficiency for a given $L E p$ depends on wind speed, meaning that the radiative and convective components 
of $L E p$ do not affect evaporation in dry condition similarly. This was explained by the impact of soil heating on water vaporization below the surface. In the present study, the lack of sensitivity to wind speed may be induced by (i) the fact that the experiments do not explore strong wind conditions (the maximum value of the wind speed measurements averaged between 10 am to $4 \mathrm{pm}$ is $7 \mathrm{~m} \mathrm{~s}^{-1}$ at Auradé and $4 \mathrm{~m} \mathrm{~s}^{-1}$ at Lamasquère) and (ii) the difference in computing $r_{a h}$ and $L E p$.

\section{b. Soil moisture profile}

The formulation of soil evaporative efficiency in Equation (12) is based on the mean soil moisture in the soil thickness $L$. Consequently, the vertical distribution of soil moisture is not explicitly represented by Model 3. In fact, this model representation assumes that the geometry of moisture profiles is approximately preserved during simultaneous drying and draining. This assumption is notably based on the results of Salvucci (1997), who verified the similarity of moisture profiles in a wide range of conditions by running a mechanistic model. Note however that Model 3 implicitly accounts for a decrease in soil moisture in the near surface since, as stated earlier, the increase of $P$ with soil thickness is attributed to a change in the weight of the surface layer which controls evaporation.

In practice, the non-explicit representation of soil moisture profile in the formulation is likely to affect the parameterization of $P$ in the case of extremely different profiles. In particular, soil evaporative efficiency would be different for a soil water mainly contained near the soil surface and for a soil water mainly contained near the bottom of the soil thickness, whereas modeled $\beta$ would only vary with the mean soil moisture. To assess the impact of 
soil moisture profile on model predictions, let introduce a variable $D$ defined as

$$
D=\frac{1}{\theta_{L} L} \int_{0}^{L} \theta(l) \times l d l
$$

with $\theta_{L}$ being the mean soil moisture of soil layer $L$. The variable $D$ describes the mean depth of water in the layer $L$. For instance, $D$ is equal to $L / 2$ for a uniform profile, $L / 3$ for a linear profile with $\theta(0)>0$ and $\theta(L)=0$, and $2 L / 3$ for a linear profile with $\theta(0)=0$ and $\theta(L)>0$. Figure 12 plots the mean (symbols) and standard deviation (errorbars) of the ratio $D / L$ for each soil thickness and for each site. One observes that the ratio $D / L$ is relatively constant and close to 0.5. This suggests that the good results obtained with the parameterization of $P$ in Equation (13) might be due to a relatively similar geometry of moisture profiles throughout the study period, and for the four different soil thicknesses. Note that a constant value for $A_{3}$ and $B_{3}$ is expected to be rather adapted for irrigated fields, where soil moisture is generally larger in depth than in the near-surface, making the geometry of soil moisture profile quasi-stationary. In the case of strong change in soil moisture profile, the application of the model would theoretically require a dynamic calibration of parameter $P$.

Note that in the present study, the different layer depths are much deeper than that expected from the different remote sensing techniques (5 to $100 \mathrm{~cm}$ versus $1 \mathrm{~mm}$ to $5 \mathrm{~cm}$ ). Future verification tests should be made to assess the similarity of moisture profiles in thinner soil layers. 


\section{c. Soil type}

The variability of $P$ due to soil texture and structure is represented by the value of parameters $A_{3}$ and $B_{3}$ (see Table 2). One observes that $A_{3}$ and $B_{3}$ are relatively close for Auradé and Lamasquère sites. Note that the textural dependance of $\left(A_{3}, B_{3}\right)$ should be investigated using a large variety of soils. Also, soil roughness may have a significant effect. Data collected over long time periods should be used to evaluate the impact of agricultural practices on $A_{3}$ and $B_{3}$.

The main advantage of the generic formulation in Equation (12) is to offer the possibility of calibrating its empirical parameters using remote sensing observations. More specifically, $A_{3}$ and $B_{3}$ could be extracted by (i) deriving different expressions of soil evaporative efficiency using multi-band (multi-sensing depth) microwave-derived soil moisture as input to Equation (12) (ii) estimating soil evaporative efficiency using remotely sensed surface temperature (e.g. Nishida et al. 2003) and (iii) matching the different expressions of modeled and observed soil evaporative efficiency. Alternatively, relationships between empirical parameters $\left(A_{3}, B_{3}\right)$ and measurable soil properties could be investigated as a complementary approach.

\section{Conclusions}

A new analytical expression of soil evaporative efficiency (defined as the ratio of actual to potential soil evaporation) is developed to extend the validity domain of previous formulations to soil layers with an arbitrary thickness. The soil evaporative efficiency is written $\left[0.5-0.5 \cos \left(\pi \theta_{L} / \theta_{\max }\right)\right]^{P}$ with $\theta_{L}$ being the water content in the soil layer of thickness $L$ 
$\theta_{\max }$ the soil moisture at saturation and $P$ a function of $L$ and potential soil evaporation. The main advantage of the new formulation is to predict soil evaporative efficiency in both energy-driven (for $P<0.5$ ) and moisture-driven (for $P>0.5$ ) conditions. For $P=0.5$, an equilibrium state is identified when retention forces in the soil compensate the evaporative demand above the soil surface. The approach is tested at two sites in southwestern France using in situ measurements of actual evaporation, potential evaporation and soil moisture at five different depths $(5,10,30$ and $60 / 100 \mathrm{~cm})$ collected in summer. The performance of the new approach is compared to that of the classical resistance-based one applied to the $0-5 \mathrm{~cm}$ soil layer. The root mean square difference and the correlation coefficient between modeled and observed soil evaporative efficiency is $0.09 \pm 0.02(-)$ and $0.90 \pm 0.02$ for the new formulation against $0.15 \pm 0.02(-)$ and $0.71 \pm 0.07$ for the resistance-based approach, respectively. Moreover, the model is able to represent soil evaporation process with a similar accuracy for various soil thicknesses up to $100 \mathrm{~cm}$.

The parameterization of parameter $P$ as function of $L E p$ indicates that the soil evaporative efficiency $\beta$ cannot be considered as a function of soil moisture alone, since it also depends on potential evaporation. Moreover, the effect of potential evaporation on $\beta$ appears to be equivalent to that of soil thickness on $\beta$. This equivalence is physically interpreted as an increase of retention forces in the soil in reaction to an increase in potential evaporation.

Additional future verification tests should be forthcoming to include a variety of sites in different climates within a variety of soils before higher support can be assigned to this analytical approach. In particular, the vertical variability of paramater $P$ in the top meter and its stability over long time periods need to be investigated.

This model representation is expected to facilitate the coupling of land surface models 
with multi-sensor remote sensing data. On one hand, the combination of multi-spectral data as in Merlin et al. (2008) requires accounting for the difference in sensing depth. On the other hand, the assimilation of data into land surface models as in Calvet and Bessemoulin (1998) requires the adequacy between the thickness of modeled soil layer and the depth of observation. A unique model that applies to soil layers with an arbitrary thickness is a way to achieve both objectives. 


\section{REFERENCES}

Béziat, P., E. Ceschia, and G. Dedieu, 2009: Carbon balance of a three crop succession over two cropland sites in South West France. Agr. For. Meteor., 149 (10), 1628-1645, doi:10.1016/j.agrformet.2009.05.004.

Calvet, J.-C. and P. Bessemoulin, 1998: Retrieving the root-zone soil moisture from surface soil moisture or temperature estimates: A feasibility study based on field measurements. J. Appl. Meteorol., 37 (4), 371-386.

Camillo, P. J. and R. J. Gurney, 1986: A resistance parameter for bare soil evaporation models. Soil Sci., 141, 95-105.

Chanzy, A., 1991: Modélisation simplifiée de l'évaporation d'un sol nu utilisant l'humidité et la température de surface accessibles par télédétection. PhD thesis, INAPG Institut National Agronomique Paris-Grignon, Thiverval-Grignon, France, 221 pp.

Chanzy, A. and L. Bruckler, 1993: Significance of soil surface moisture with respect to daily bare soil evaporation. Water Resour. Res., 29 (4), 1113-1125.

Chanzy, A., M. Mumen, and G. Richard, 2008: Accuracy of top soil moisture simulation using a mechanistic model with limited soil characterization. Water Resour. Res., 44 (W03432), doi:10.1029/2006WR005765.

Choudhury, B., R. J. Reginato, and S. B. Idso, 1986: An analysis of infrared temperature observations over wheat and calculation of latent heat flux. Agr. For. Meteor., 37, 75-88. 
Cosby, B. J., G. M. Hornberger, R. B. Clapp, and T. R. Ginn, 1984: A statistical exploration of the relationships of soil moisture characteristics to the physical properties of soils. Water Resour. Res., 20 (6).

Crow, W. T., W. P. Kustas, and J. H. Prueger, 2008: Monitoring root-zone soil moisture through the assimilation of a thermal remote sensing-based soil moisture proxy into a water balance model. Remote Sens. Environ., 112, 1268-1281.

Daamen, C. C. and L. P. Simmonds, 1996: Measurement of evaporation from bare soil and its estimation using surface resistance. Water Resour. Res., 32 (5), 1393-1402.

Deardorff, J. W., 1978: Efficient prediction of ground temperature and moisture with inclusion of a layer of vegetation. J. Geophys. Res., 83, 1889-1903.

Fritton, D. D., D. Kirkham, and R. H. Shaw, 1967: Soil water and chloride redistribution under various evaporation potentials. Soil Sci. Soc. Am., 31, 599-603.

Fuchs, M. and C. Tanner, 1967: Evaporation from a drying soil. J. Appl. Meteorol., 6, $852-857$.

Jacquemin, B. and J. Noilhan, 1990: Sensitivity study and validation of land surface parameterization using the HAPEX-MOBILHY data set. Bound.-Layer Meteor., 52, 93-134.

Jolliffe, I. T., 2002: Principal Component Analysis (2nd Ed.). Springer, 502 pp., ISBN 0387954422.

Komatsu, T. S., 2003: Towards a robust phenomenological expression of evaporation efficiency for unsaturated soil surfaces. J. Appl. Meteor., 42, 1330-1334. 
Kondo, J., N. Saigusa, and T. Sato, 1990: A parameterization of evaporation from bare soil surface. J. Appl. Meteor., 29, 385-389.

Kustas, W. P., T. J. Schmugge, K. S. Humes, T. J. Jackson, R. Parry, M. A. Weltz, and M. S. Moran, 1993: Relationships between evaporative fraction and remotely sensed vegetation index and microwave brightness temperature for semiarid rangelands. J. Appl. Meteorol., 32, 1781-1790.

Kustas, W. P., X. Zhan, and T. J. Schmugge, 1998: Combining optical and microwave remote sensing for mapping energy fluxes in a semiarid watershed. Remote Sens. Environ., 64, $116-131$.

Lawrence, D. M., P. E. Thornton, K. W. Oleson, and G. B. Bonan, 2007: The partitioning of evapotranspiration into transpiration, soil evaporation, and canopy evaporation in a GCM: impacts on land-atmosphere interaction. J. Hydrometeor., 8, 862-880.

Lee, T. J. and R. A. Pielke, 1992: Estimating the soil surface specific humidity. J. Appl. Meteor., 31, 480-484.

Liu, S., D. Mao, and L. Jia, 2007: Evaluating parameterizations of aerodynamic resistance to heat transfer using field measurements. Hydrol. Earth Syst. Sci., 11, 769-783.

Mahfouf, J. F. and J. Noilhan, 1991: Comparative study of various formulations of evaporation from bare soil using in situ data. J. Appl. Meteor., 30, 1354-1365.

Merlin, O., J. P. Walker, A. Chehbouni, and Y. Kerr, 2008: Towards deterministic downscaling of SMOS soil moisture using MODIS derived soil evaporative efficiency. Remote Sens. Environ., 112, 3935-3946, doi:10.1016/j.rse.2008.06.012. 
Mihailović, D. T., R. A. Pielke, B. Rajković, T. J. Lee, and M. Jeftić, 1993: A resistance representation of schemes for evaporation from bare and partly plant-covered surfaces for use in atmospheric models. J. Appl. Meteor., 32, 1038-1054.

Monteith, J. L., 1981: Evaporation and surface temperature. Q. J. Roy. Meteor. Soc., 107, $1-27$.

Nishida, K., R. R. Nemani, J. M. Glassy, and S. W. Running, 2003: Development of an evapotranspiration index from Aqua/MODIS for monitoring surface moisture status. IEEE Trans. Geosci. Remote Sens., 41 (2), 493-501.

Noilhan, J. and S. Planton, 1989: A simple parameterization of land surface processes for meteorological models. Mon. Wea. Rev., 117, 536-549.

Passerat de Silans, A., 1986: Transferts de masse et de chaleur dans un sol stratifié soumis à une excitation atmosphérique naturelle: comparaison modèle-expérience. Thèse de doctorat, Inst. Natl. Polytech. de Grenoble, France.

Perrier, A., 1975: Etude physique de l'évapotranspiration dans des conditions naturelles, II, Expressions et paramètres donnant l'évapotranspiration réelle d'une surface mince. Ann. Agron., 26 (2), 105-123.

Philip, J. R., 1957: Evaporation, and moisture and heat fields in the soil. J. Atmos. Sci., 14, 354-366.

Pitman, A. J., 2003: The evolution of, and revolution in, land surface schemes designed for climate models. Int. J. Climatol., 23 (5), 479-510. 
Salvucci, G. D., 1997: Soil and moisture independent estimation of two-stage evaporation from potential evaporation and albedo or surface temperature. Water Resour. Res., 33 (1), $111-122$.

Saravanapavan, T. and G. D. Salvucci, 2000: Analysis of rate-limiting processes in soil evaporation with implications for soil resistance models. Adv. Water Res., 23, 493-502.

Sellers, P. J., M. D. Heiser, and F. G. Hall, 1992: Relations between surface conductance and spectral vegetation indices at intermediate $\left(100 \mathrm{~m}^{2}\right.$ to $\left.15 \mathrm{~km}^{2}\right)$ length scales. J. Geophys. Res., 97 (D17), 19 033-19059.

Shuttleworth, W. J. and J. S. Wallace, 1985: Evaporation from sparse crops-an energy combination theory. Q. J. Roy. Meteor. Soc., 111, 839-855.

van de Griend, A. A. and M. Owe, 1994: Bare soil surface resistance to evaporation by vapor diffusion under semiarid conditions. Water Resour. Res., 30 (2), 181-188.

Wallace, J. S., 1995: Calculating evaporation: resistance to factors. Agr. For. Meteorol., 73, $353-366$.

Yamanaka, T., A. Takeda, and J. Shimada, 1998: Evaporation beneath the soil surface: some observational evidence and numerical experiments. Hydrol. Process., 12, 2193-2203.

Yamanaka, T., A. Takeda, and F. Sugita, 1997: A modified surface-resistance approach for representing bare-soil evaporation: wind tunnel experiments under various atmospheric conditions. Water Resour. Res., 33 (9), 2117-2128. 


\section{List of Tables}

1 Root mean square difference (RMSD), correlation coefficient (R), slope and mean difference (MD) between the evaporative efficiency simulated by uncalibrated Model 1, 2 and 3 and observed evaporative efficiency for each site.

2 Calibration coefficients for Model 1,2 and 3. The p-value is also presented for Model 1 and 3. It is an indicator of the statistical significance of the linear regressions used to estimate $\left(A_{1}, B_{1}\right)$ and $\left(A_{3}, B_{3}\right)$.

3 Root mean square difference (RMSD), correlation coefficient (R), slope and mean difference (MD) between the evaporative efficiency simulated by calibrated Model 1, 2 and 3 and observed evaporative efficiency for each site. 
TABLE 1. Root mean square difference (RMSD), correlation coefficient (R), slope and mean difference (MD) between the evaporative efficiency simulated by uncalibrated Model 1, 2 and 3 and observed evaporative efficiency for each site.

\begin{tabular}{|c|c|c|c|c|c|}
\hline Site & Model & RMSD (-) & $\mathrm{R}(-)$ & Slope (-) & $\mathrm{MD}(-)$ \\
\hline \multirow[t]{3}{*}{ Auradé } & 1 & 0.21 & 0.45 & 0.13 & -0.12 \\
\hline & 2 & 0.64 & 0.25 & 0.07 & +0.62 \\
\hline & 3 & 0.14 & 0.84 & 0.44 & +0.08 \\
\hline \multirow[t]{3}{*}{ Lamasquère } & 1 & 0.17 & 0.55 & 0.30 & -0.06 \\
\hline & 2 & 0.66 & 0.49 & 0.08 & +0.64 \\
\hline & 3 & 0.18 & 0.66 & 0.50 & +0.11 \\
\hline
\end{tabular}


TABle 2. Calibration coefficients for Model 1,2 and 3. The p-value is also presented for Model 1 and 3. It is an indicator of the statistical significance of the linear regressions used to estimate $\left(A_{1}, B_{1}\right)$ and $\left(A_{3}, B_{3}\right)$.

\begin{tabular}{|c|c|c|c|c|}
\hline Site & Model & Coefficients & Unit & p-value \\
\hline \multirow[t]{5}{*}{ Auradé } & 1 & $A_{1}=13.7$ & - & $1 \times 10^{-12}$ \\
\hline & & $B_{1}=15.7$ & - & \\
\hline & 2 & $\theta_{c 0}=0.34$ & vol./vol. & n.a. \\
\hline & 3 & $A_{3}=0.0088$ & - & 0.06 \\
\hline & & $B_{3}=60$ & $\mathrm{~W} \mathrm{~m}^{-2}$ & \\
\hline \multirow[t]{5}{*}{ Lamasquère } & 1 & $A_{1}=10.0$ & - & $7 \times 10^{-7}$ \\
\hline & & $B_{1}=7.9$ & - & \\
\hline & 2 & $\theta_{c 0}=0.36$ & vol./vol. & n.a. \\
\hline & 3 & $A_{3}=0.011$ & - & 0.01 \\
\hline & & $B_{3}=53$ & $\mathrm{~W} \mathrm{~m}^{-2}$ & \\
\hline
\end{tabular}


TABLE 3. Root mean square difference (RMSD), correlation coefficient (R), slope and mean difference (MD) between the evaporative efficiency simulated by calibrated Model 1, 2 and 3 and observed evaporative efficiency for each site.

\begin{tabular}{|c|c|c|c|c|c|c|}
\hline Site & Soil layer & Model & RMSD (-) & $\mathrm{R}(-)$ & Slope (-) & $\operatorname{MD~(-)~}$ \\
\hline \multirow[t]{6}{*}{ Auradé } & $L 1$ & 1 & 0.13 & 0.78 & 0.76 & +0.05 \\
\hline & $L 1$ & 2 & 0.22 & 0.82 & 0.13 & +0.15 \\
\hline & $L 1$ & 3 & 0.07 & 0.92 & 0.83 & +0.01 \\
\hline & $L 2$ & 3 & 0.08 & 0.92 & 0.84 & +0.01 \\
\hline & $L 3$ & 3 & 0.08 & 0.92 & 0.91 & +0.03 \\
\hline & $L 4$ & 3 & 0.09 & 0.88 & 0.92 & +0.01 \\
\hline \multirow[t]{6}{*}{ Lamasquère } & $L 1$ & 1 & 0.16 & 0.63 & 0.53 & +0.01 \\
\hline & $L 1$ & 2 & 0.22 & 0.65 & 0.13 & +0.13 \\
\hline & $L 1$ & 3 & 0.10 & 0.90 & 0.97 & +0.03 \\
\hline & $L 2$ & 3 & 0.09 & 0.90 & 0.98 & +0.02 \\
\hline & $L 3$ & 3 & 0.10 & 0.89 & 0.96 & +0.03 \\
\hline & $L 4$ & 3 & 0.10 & 0.86 & 0.82 & +0.00 \\
\hline
\end{tabular}




\section{List of Figures}

1 Time series of soil moisture measurements at 5, 10, 30 and $60(100) \mathrm{cm}$ in 2006 (2005) for Auradé (Lamasquère). The study period is indicated for each site.

2 Schematic diagram of the experimental set up. The method for estimating the soil moisture value integrated over $0-5,0-10$ and $0-30 \mathrm{~cm}$ from in situ measurements at 5, 10 and $30 \mathrm{~cm}$ depth is illustrated.

3 Observed evaporative efficiency $\beta_{\text {obs }}$ as a function of observed soil moisture $\theta_{L 1}$ for each site separately.

4 Intercomparison of Model 1, 2 and 3. Model 3 is able to approximately fit Model 1 and 2 by changing the value of parameter $P$.

5 Soil evaporative efficiency simulated by Model 3 as a function of soil moisture, for different values of $P$. Evaporative (soil and atmospheric) conditions switch from energy-driven for $P<0.5$ to moisture-driven for $P>0.5$. An equilibrium state is obtained at $P=0.5$.

$6 \quad$ Soil evaporative efficiency simulated by uncalibrated Model 1,2 and 3 versus observed soil evaporative efficiency.

7 Retrieved soil resistance as a function of near-surface soil moisture for each site separately.

8 Soil evaporative efficiency simulated by calibrated Model 1, 2 and 3 versus observed soil evaporative efficiency at each site. In the case of Model 3, soil evaporative efficiency is simulated for four different soil layers. 
9 Retrieved parameter $P$ as a function of potential evaporation $L E p$.

10 The ratio of retrieved parameter $P$ to potential evaporation $L E p$ is plotted against normalized soil thickness $(L-L 1) / L 1$.

11 The correlation circle is plotted for each site. Three variables are represented: retrieved parameter $P$, potential evaporation $L E p$ and wind speed $u$. All variables were centered and normalized prior to PC (Principal Component) analysis.

12 The ratio of the mean depth $D$ of soil water to soil thickness $L$ is plotted against normalized thickness $(L-L 1) / L 1$ for each site. 

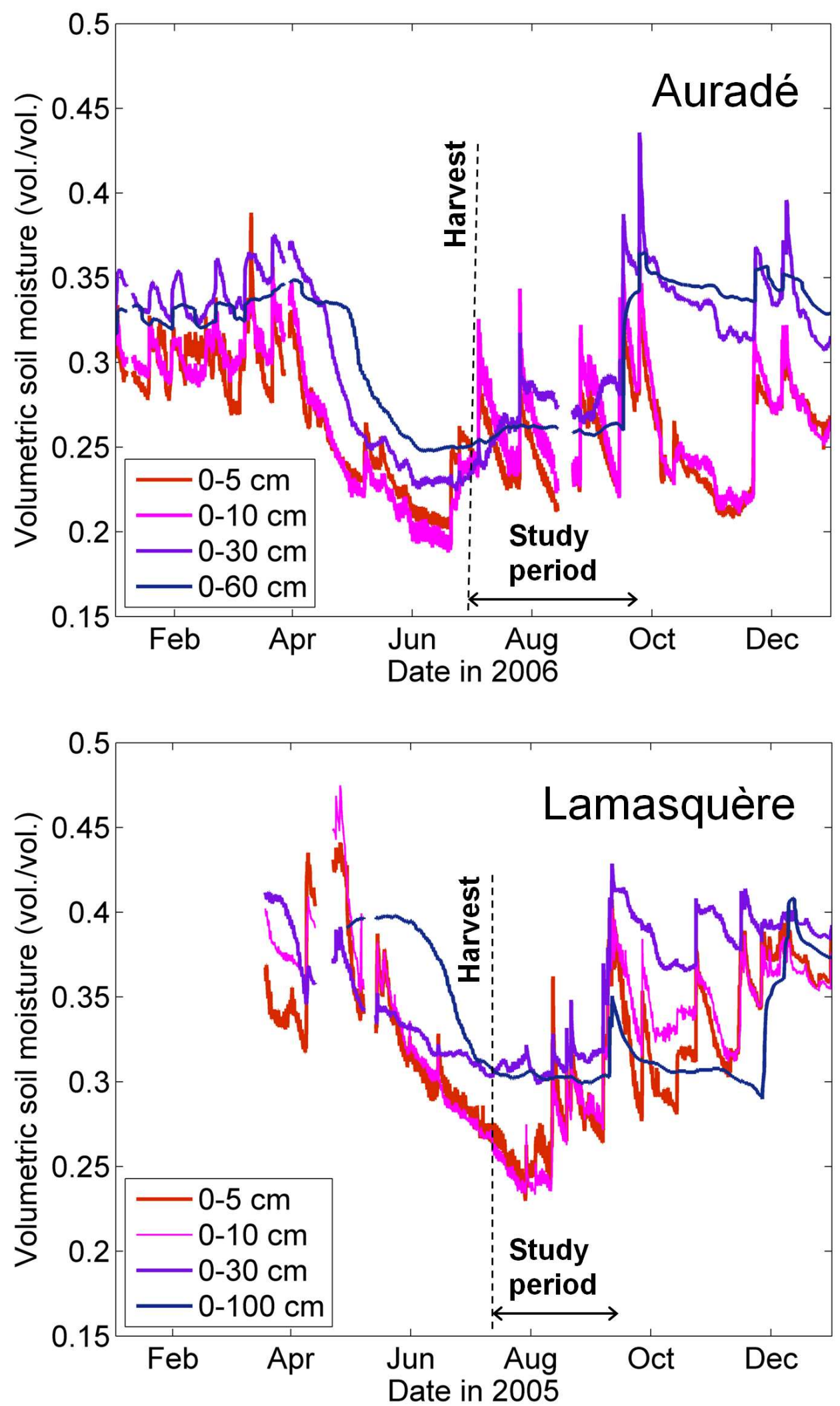

Fig. 1. Time series of soil moisture measurements at 5, 10, 30 and $60(100) \mathrm{cm}$ in 2006 (2005) for Auradé (Lamasquère). The study period is indicated for each site. 


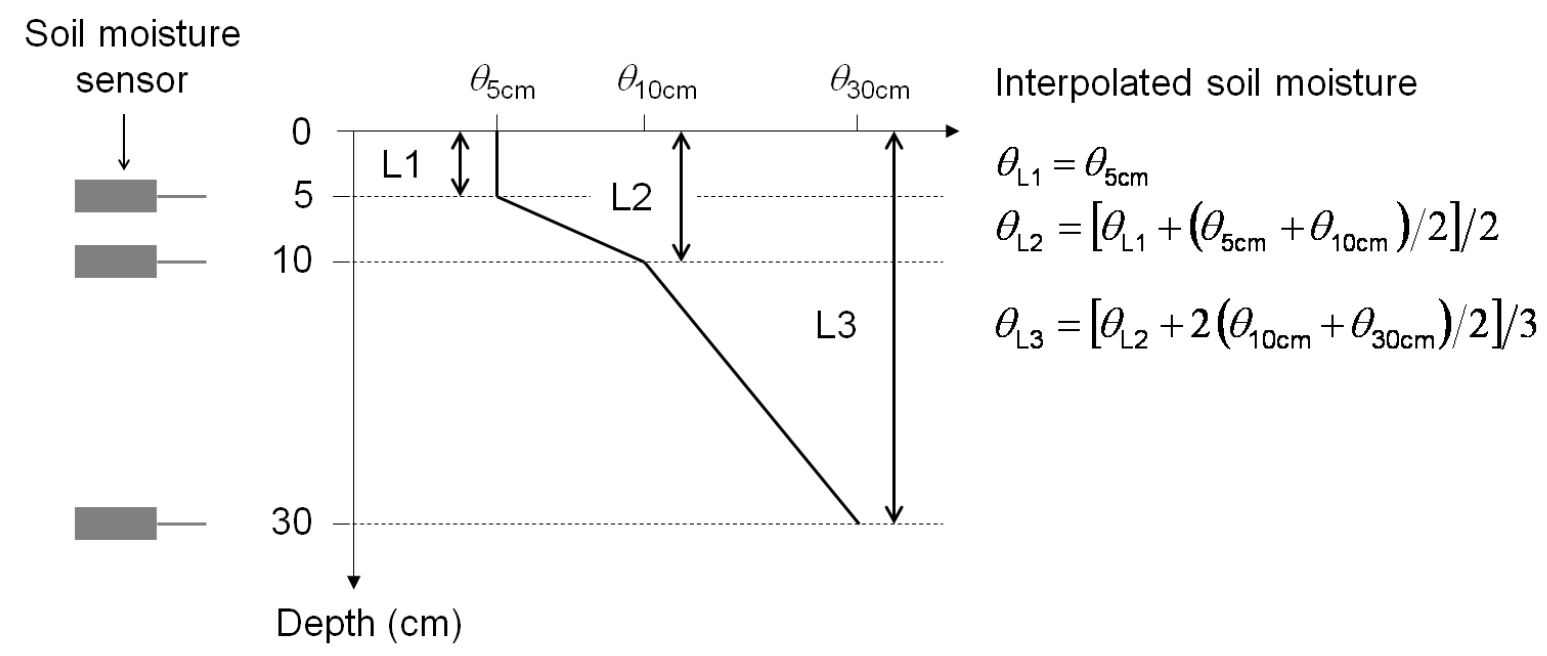

FIG. 2. Schematic diagram of the experimental set up. The method for estimating the soil moisture value integrated over $0-5,0-10$ and $0-30 \mathrm{~cm}$ from in situ measurements at 5,10 and $30 \mathrm{~cm}$ depth is illustrated. 

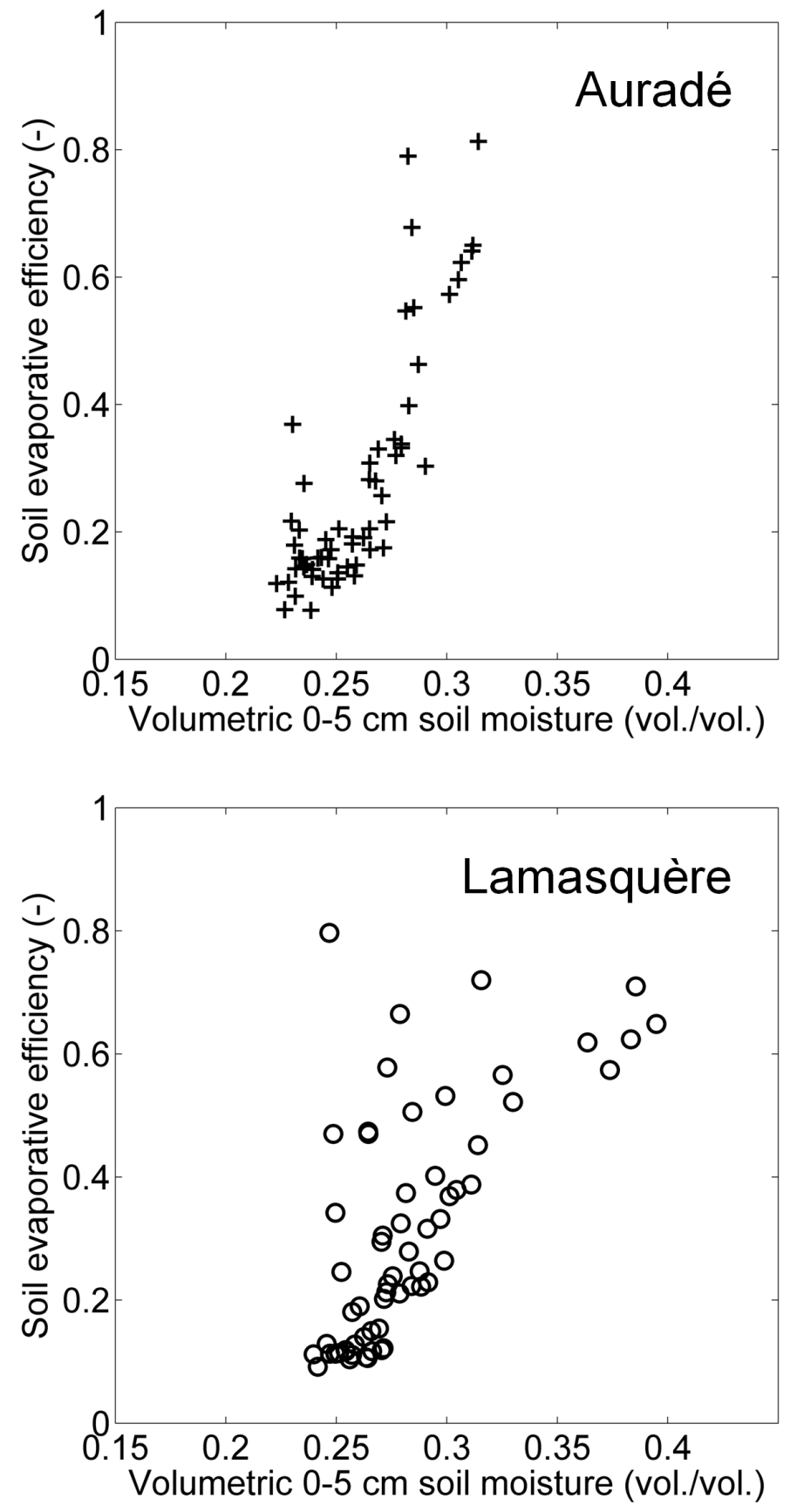

FIG. 3. Observed evaporative efficiency $\beta_{o b s}$ as a function of observed soil moisture $\theta_{L 1}$ for each site separately. 


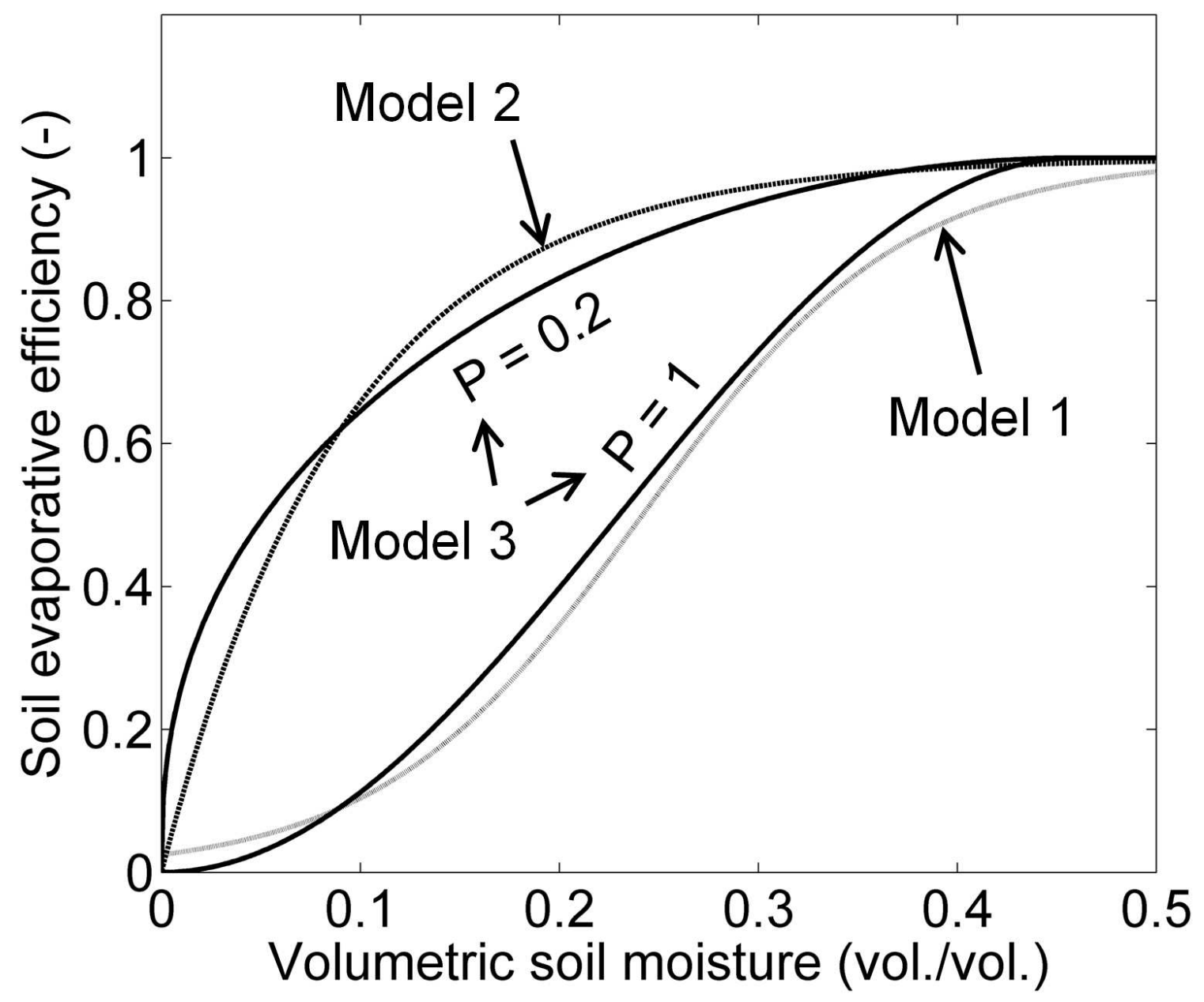

FIG. 4. Intercomparison of Model 1,2 and 3. Model 3 is able to approximately fit Model 1 and 2 by changing the value of parameter $P$. 


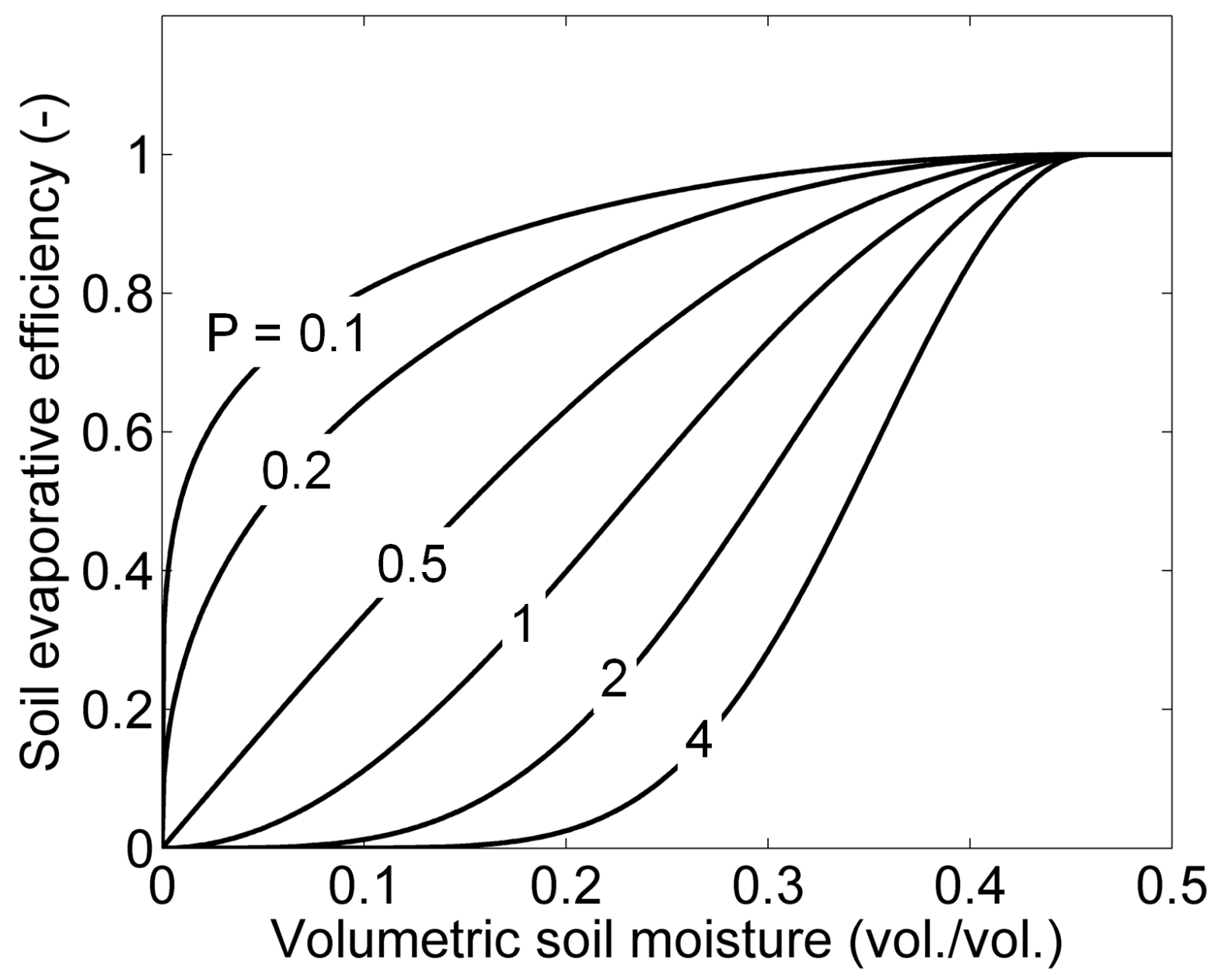

FIG. 5. Soil evaporative efficiency simulated by Model 3 as a function of soil moisture, for different values of $P$. Evaporative (soil and atmospheric) conditions switch from energydriven for $P<0.5$ to moisture-driven for $P>0.5$. An equilibrium state is obtained at $P=0.5$. 

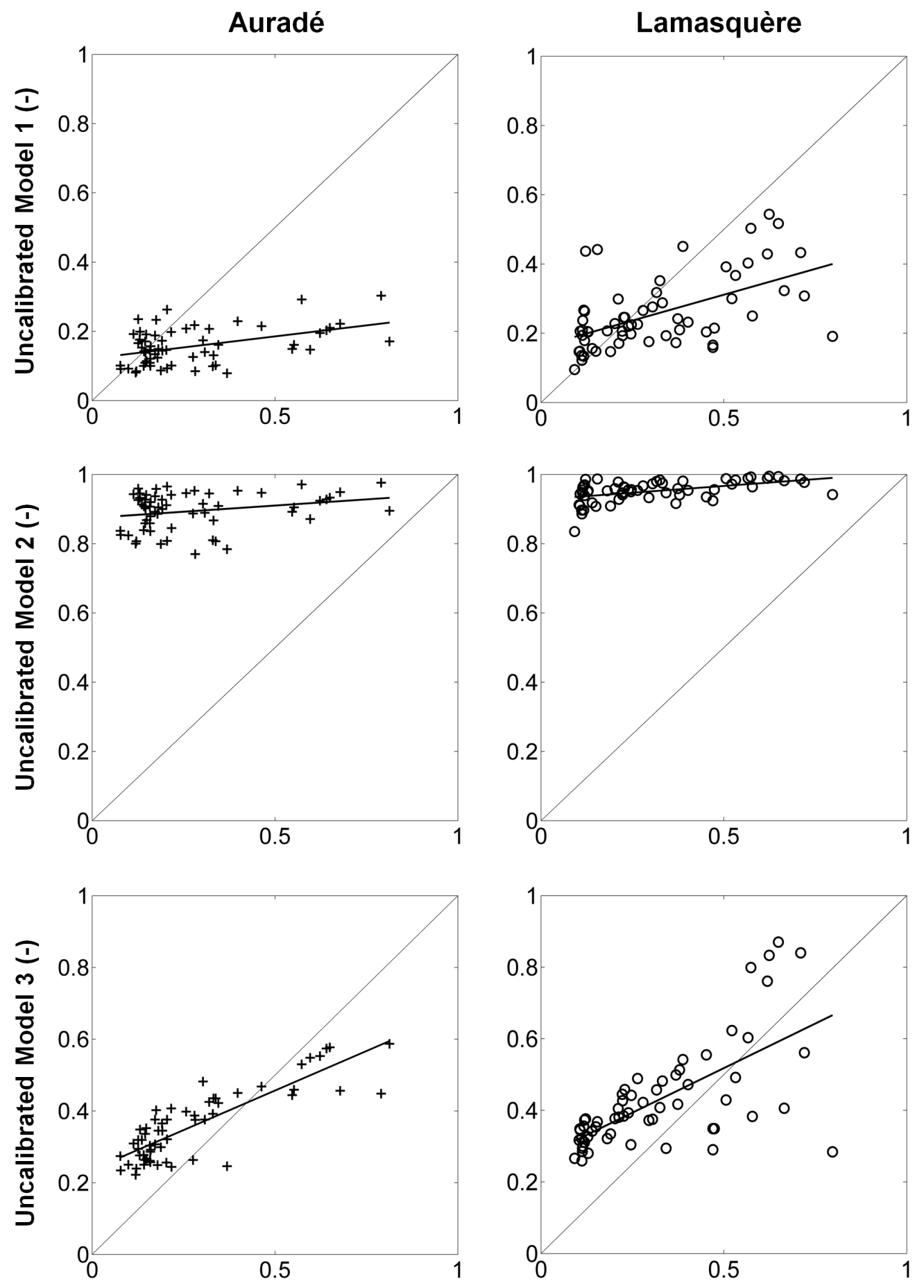

Observed evaporative efficiency (-) Observed evaporative efficiency (-)

Fig. 6. Soil evaporative efficiency simulated by uncalibrated Model 1, 2 and 3 versus observed soil evaporative efficiency. 

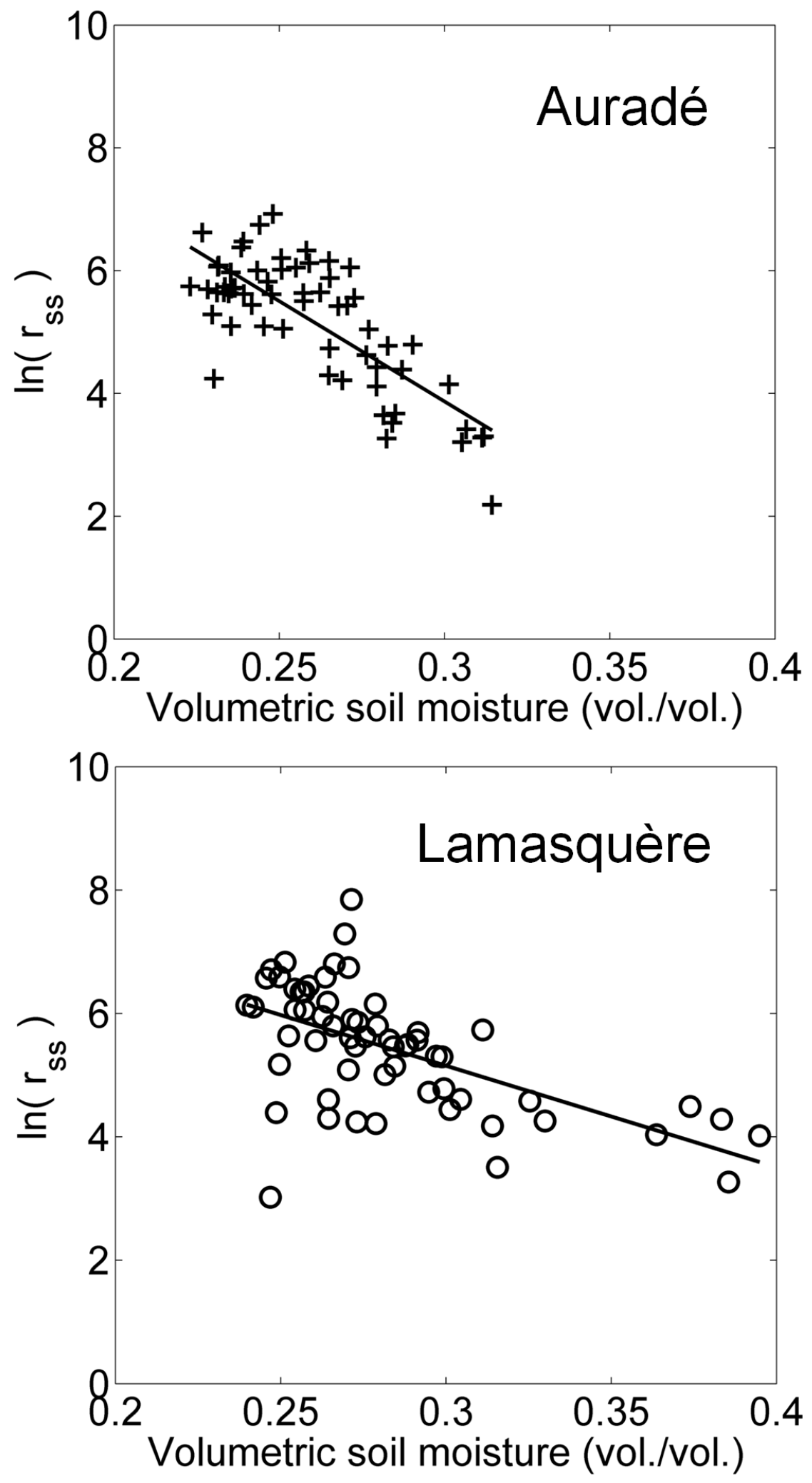

FIG. 7. Retrieved soil resistance as a function of near-surface soil moisture for each site separately. 

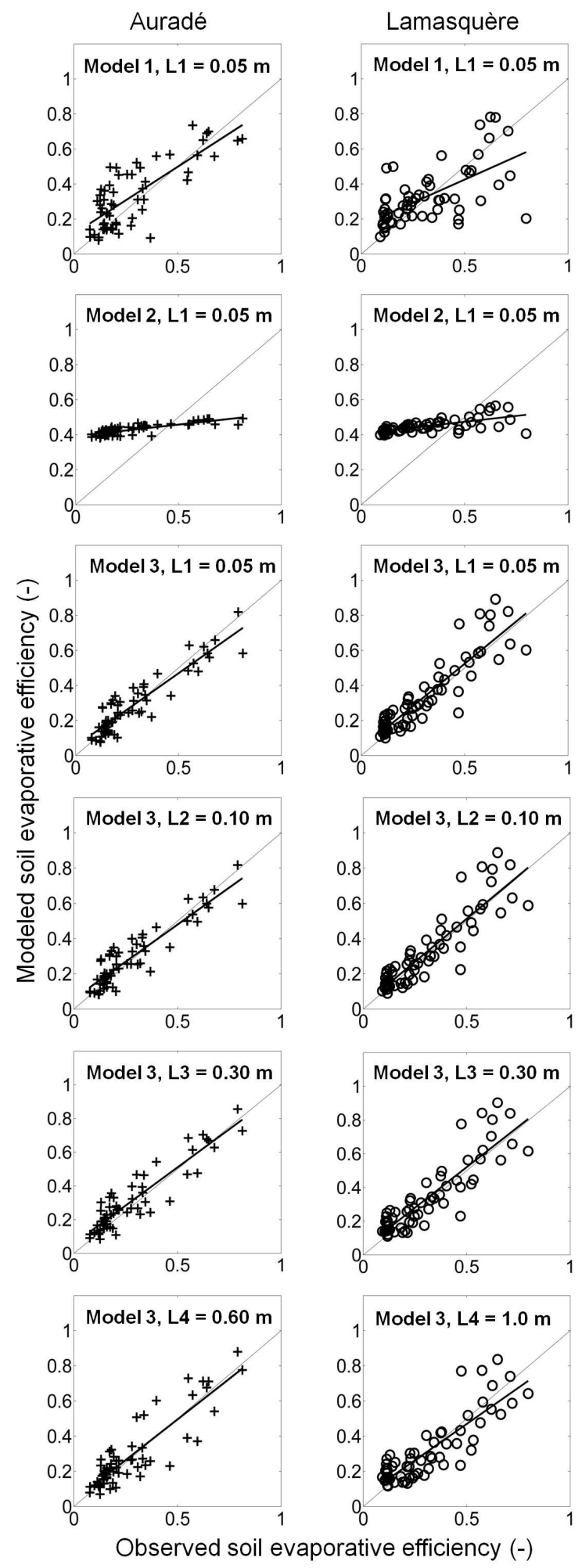

FIG. 8. Soil evaporative efficiency simulated by calibrated Model 1, 2 and 3 versus observed soil evaporative efficiency at each site. In the case of Model 3, soil evaporative efficiency is simulated for four different soil layers. 

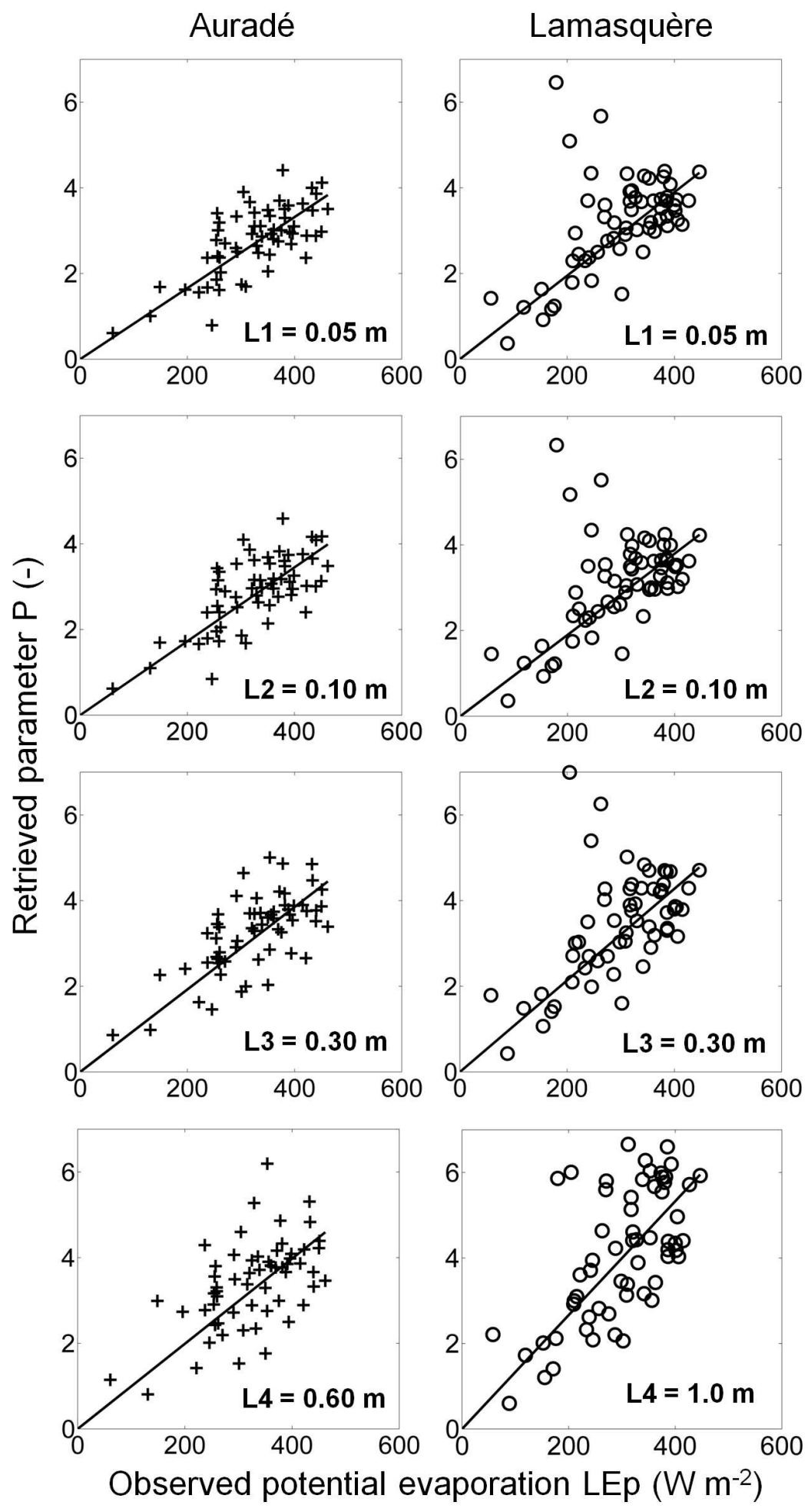

FIG. 9. Retrieved parameter $P$ as a function of potential evaporation $L E p$. 


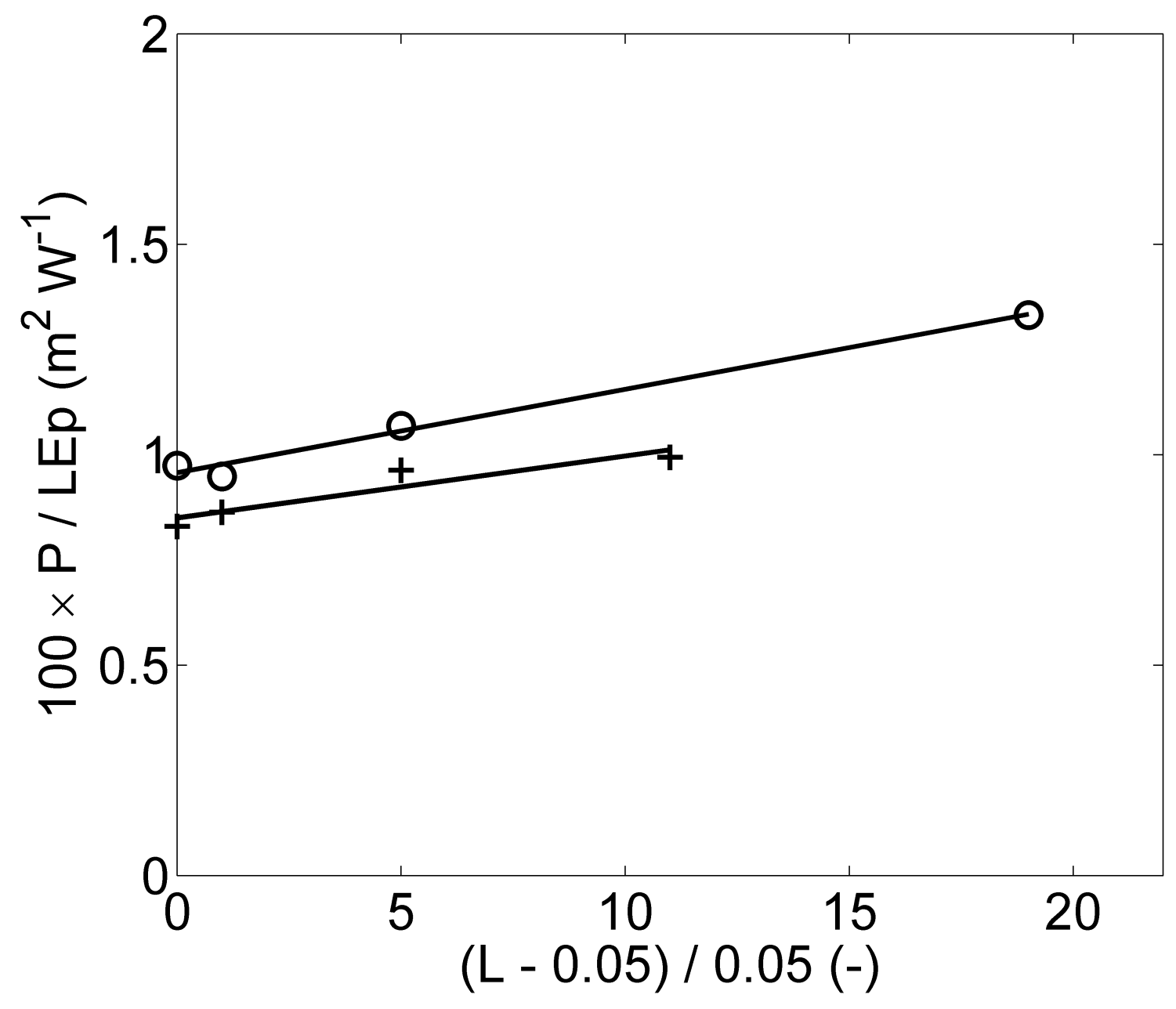

FIG. 10. The ratio of retrieved parameter $P$ to potential evaporation $L E p$ is plotted against normalized soil thickness $(L-L 1) / L 1$. 

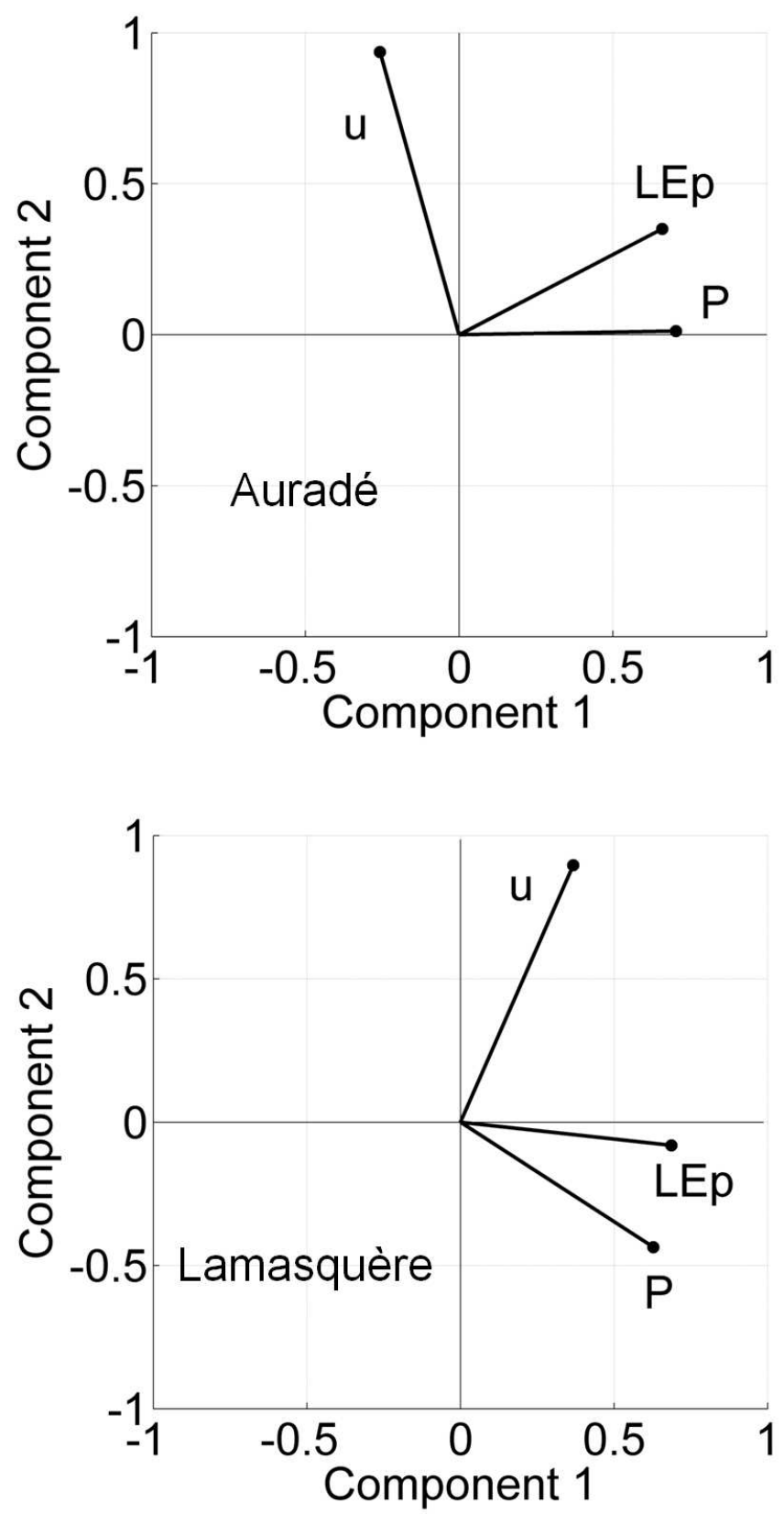

FIG. 11. The correlation circle is plotted for each site. Three variables are represented: retrieved parameter $P$, potential evaporation $L E p$ and wind speed $u$. All variables were centered and normalized prior to PC (Principal Component) analysis. 


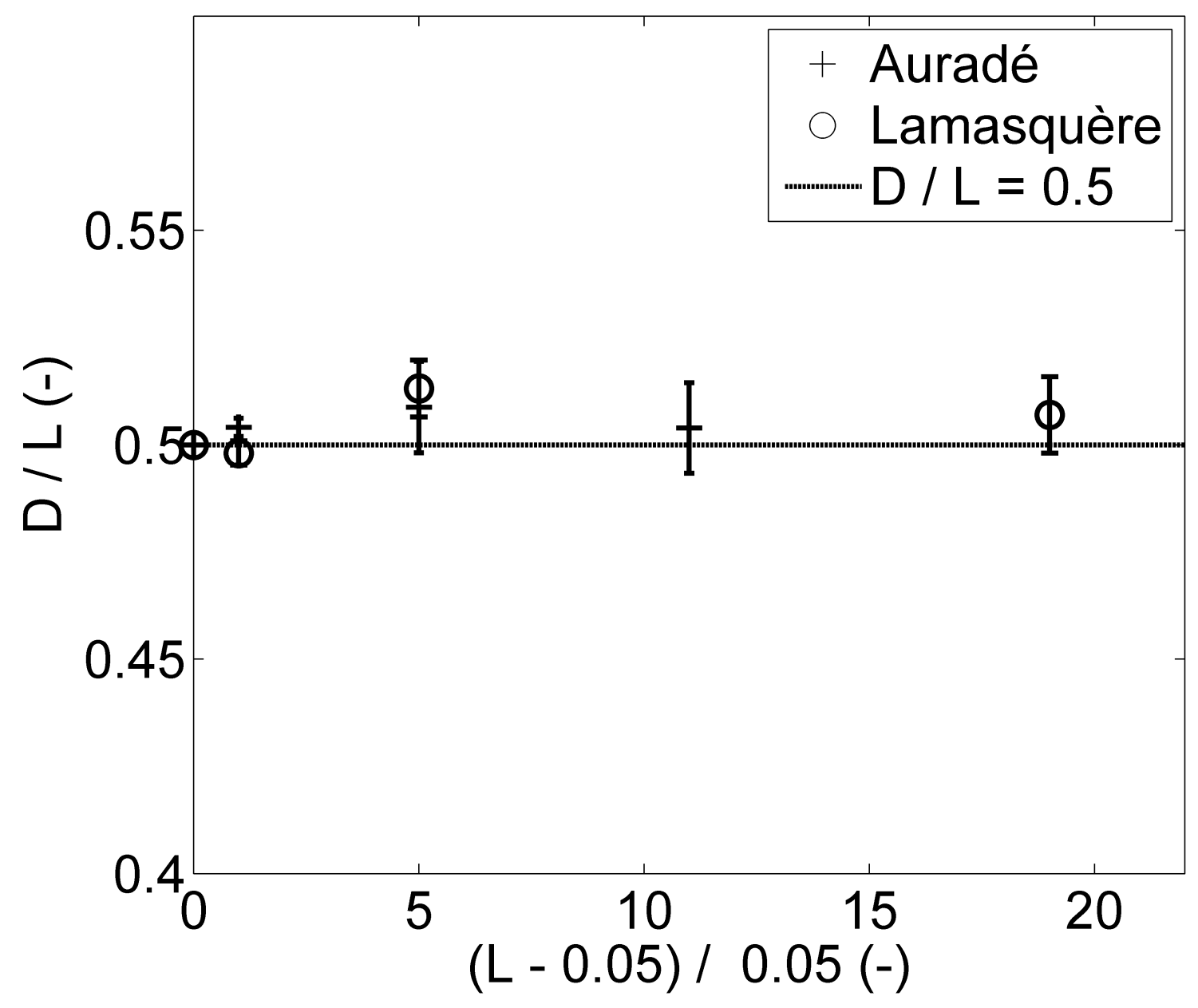

FIG. 12. The ratio of the mean depth $D$ of soil water to soil thickness $L$ is plotted against normalized thickness $(L-L 1) / L 1$ for each site. 